\title{
O PAPEL DAS CIDADES (INTER) MÉDIAS PARA O \\ DESENVOLVIMENTO REGIONAL: um estudo a partir dos centros sub- regionais (Pau dos Ferros-RN, Cajazeiras-PB e Sousa-PB)
}

\author{
THE ROLEOF INTERMEDIATE CITIESFOR REGIONAL \\ DEVELOPMENT: a study from thesub-regional centers(Pau dos Ferros- \\ RN, Cajazeiras-PB andSousa-PB)
}

\author{
Joseney Rodrigues de Queiroz Dantas \\ Doutoranda do PPGCS/UFRN; \\ Docente do DEC/CAMEAM/UERN. \\ joseney_queiroz@hotmail.com
}

\begin{abstract}
Maria do Livramento Miranda Clementino
Professora Titular do DPP/UFRN; Professora do PPGCS/UFRN e PPEUR/UFRN.
\end{abstract}

clement@ufrnet.br

\section{RESUMO}

Os estudos sobre as cidades médias no Brasil ganham destaque no meio acadêmico e na elaboração de políticas públicas nos anos 1970. Com o novo contexto econômico da globalização e as reconfigurações territoriais, alguns autores tem proposto a utilização do termo cidade intermédia ou cidade intermediária, em cujo escopo está embutido critérios de natureza qualitativa, inclusive a idéia de um espaço de relações estruturado em nós e fluxos. $\mathrm{Na}$ região Nordeste, o processo de urbanização foi lento, atomizado, geográfico e economicamente disperso, o que resultou numa rede urbana truncada, constituída principalmente por suas nove capitais regionais e cerca de duas dezenas de cidades de porte médio, em sua maioria interiorizadas.É a partir dessa 'rede urbana nordestina interiorizada' que buscamos compreender as funções fundamentais de Pau dos Ferros(RN), Souza e Cajazeiras(PB) no desenvolvimento regional e o papel que elas desempenham nas suas respectivas regiões de influência que perpassam a raia divisória RN-PB-CE. À priori essas funções seriam oferecer empregos suficientes para acolher a população rural do entorno e absorver a população dos núcleos urbanos saturados e facilitar as condições de vida. Em termos gerais, o que se pode observar é que o comércio e os serviços tem uma participação relativa muito alta na composição do PIB das três cidades, reforçado pela participação do Estado, com destaque para a oferta dos serviços de educação, inclusive superior e saúde, além da oferta de empregos, notadamente no comércio e nos serviços públicos, o que nos permite tratá-las à priori como cidades (inter) médias.

Geo UERJ - Ano 15, no. 24, v. 1, $1^{\circ}$ semestre de 2013 p. 228-255

ISSN: 1415-7543E-ISSN: 1981-9021

http://www.e-publicacoes.uerj.br/index.php/geouerj 
Palavras-chave: cidades médias, rede urbana nordestina interiorizada, centros sub-regionais, desenvolvimento regional, Pau dos Ferros-Cajazeiras-Sousa.

\begin{abstract}
Studies onmedium-sized citiesin Brazilgain prominencein the academicandpublic policies developmentin the 1970s. With thenew economic contextof globalizationandterritorialreconfigurations, some authorshaveproposedthe useof the termintermediate cityortownintermediary, whose scopeis builtonqualitativecriteria, including the idea of astructuredspace ofrelationsandflowsin us. In the Northeast, the urbanization processwas slow, fragmented,dispersed geographicand economically, which resulted in atruncatedurban network, which consists primarily ofits nineregional capitalsand abouttwo dozenmedium-sized cities, mostlyinteriorized.It is from this'urban network northeasterninteriorized' we seekto understand the fundamental functions of Pau dos Ferros(RN), Souza and Cajazeiras(PB) in regional development and the role they playin their respective regionsof influencethat permeate theraypartitionRN-PB-CE.A priorithese functionswouldofferenough jobsto accommodatethe populationsurroundingruraland absorbthe populationof urban areassaturated andeaseliving conditions.In general terms, whatcan be seenisthat tradeand serviceshas averyhighrelative sharein the PIB compositionof the three cities, reinforced by theparticipation of the state, especially the provisionof education services, including higher and health, beyondof jobs, particularly in trade andpublic services, which allows us totreat themasa prioriintermediate cities.
\end{abstract}

Keywords: medium-sized cities, urban networkNortheasterninteriorized, sub-regional centers, regional development, Pau dos Ferros-Cajazeiras-Sousa.

\title{
Introdução
}

As cidades médias tornam-se objeto de atenção nos anos 1960, nas políticas de desenvolvimento e ordenamento do território em vários países europeus. De acordo com Ferrão et al (1994), os objetivos do planejamento visavam por um lado, a continuidade do crescimento da economia, e por outro lado, corrigir eventuais desarranjos na organização do território, no sentido de evitar excessiva concentração de população e de atividades, estimulando assim, os mecanismos de desconcentração.

No Brasil, os estudos sobre "cidades médias" ganham destaque no meio acadêmico e na elaboração de políticas públicas, especialmente, com as políticas de planejamento urbano e regional a partir dos anos 1970. O processo de concentração da produção e da riqueza e o consequente processo de migração que a acompanhou, impulsionou a elaboração de políticas de desconcentração urbano-regional que visavam fortalecer cidades de médio porte no sentido

Geo UERJ - Ano 15, n⿳0.24, v. 1, $1^{\circ}$ semestre de 2013 p. 228-255

ISSN: 1415-7543E-ISSN: 1981-9021

http://www.e-publicacoes.uerj.br/index.php/geouerj 
de conter os fluxos migratórios e amenizar os problemas tipicamente urbanos, como o problema das moradias, por exemplo.

Essa política de desconcentração urbano-regional que resultou em certo fortalecimento das cidades médias foi interrompida na década de 1980, como resultado da crise instalada na economia do país, a partir da qual, a política governamental passou a priorizar a estabilidade monetária em detrimento da continuidade do projeto de desenvolvimento econômico regional, afetando não apenas as áreas mais dinâmicas do país, mas também as demais regiões.

As mudanças ocorridas na economia mundial, dentre as quais destacamos o acentuado processo de internacionalização dos fluxos de capital e de mercadorias, com seus consequentes impactos na organização da produção, parecem ter impulsionado novamente o interesse pelas chamadas cidades médias. De acordo com Amorim Filho e Serra (2001), as cidades médias continuam a ser valorizadas como fator de equilíbrio para as redes e hierarquias urbanas, bem como por exercer as funções de relação e intermediação com as grandes cidades e com as pequenas cidades e o meio rural.

É notória a existência de uma gama de análises referentes às metrópoles e às grandes cidades, o que não ocorre da mesma forma com as cidades menores, especialmente com as cidades do interior do Nordeste. Morais (1999)afirma que essas cidades de porte médio apresentam algumas características peculiares: não tem o ritmo agitado, nem o arsenal de equipamentos das grandes cidades, nem seu raio de influência, mas também não podem ser comparadas com cidades cujo raio de influência restringe-se aos limites do seu próprio município.

Nesta perspectiva, opresente artigo se propõe a estudar o papel desempenhado pelas cidades de Pau dos Ferros-RN, Cajazeiras-PB e Sousa-PB na raia divisória ${ }^{1}$ do Rio Grande do Norte-Paraíba-Ceará. A escolha dessas três cidades localizadas na região semiárida nordestina e com distância superior a $400 \mathrm{~km}$ de suas respectivas capitais (Natal e João Pessoa) se dá pelo fato da importância que essas cidades representam para o interior de seus Estados concretizada pelas amplas regiões de influência que ultrapassam suas respectivas microrregiões, se estendendo inclusive para além dos limites estaduais. Estas cidades são de certa forma beneficiadas pela concentração de fluxo de população, mercadorias e dinheiro, que circunda essa região fronteiriça entre os Estados do Rio Grande do Norte, Ceará e Paraíba. 
Ao atuarem como centro de comércio e serviços diversificados (educacional, notadamente), Pau dos Ferros-RN, Cajazeiras-PB e Sousa-PB, aparecem como Centros SubRegionais A, classificadas em terceiro lugar na hierarquia da rede urbana brasileira ${ }^{2}$, pelo mais recente estudo do IBGE sobre cidades, o REGIC - Região de Influência das Cidades. Para delimitar a hierarquia dos centros urbanos, o IBGE privilegiou a função de gestão do território, no qual avaliou os níveis de centralidade do Poder Executivo e do Poder Judiciário e de centralidade empresarial; a intensidade de relacionamentos ${ }^{3}$, e a dimensão da região de influência de cada centro, bem como as diferenciações regionais. (IBGE, 2008).

Importante salientar que a posição de polo regional, assumida pelas três cidades não é recente. Apesar de terem ocorrido algumas variações no período ${ }^{4}$, essas cidades se caracterizam como polos regionais no comando de suas respectivas regiões, estabelecendo relações próprias. Entretanto, essa "funcionalidade não homogeneíza, sendo necessário, assim, desvendar e questionar a singularidade de cada uma dessas cidades" (GARCIA \& NOGUEIRA, 2008, p. 3).

\section{Como pensar as cidades de média dimensão? algumas reflexões sobre conceitos e definições.}

O termo "cidade média", apesar de muito utilizado, não possui uma definição teórica precisa, e muito menos consensual. Nos diversos estudos existentes sobre esse tipo de cidade, é comum encontrarmos as expressões "cidade de porte médio", "cidade de média dimensão", "cidade intermédia/intermédiária", "centros regionais e sub-regionais" com o mesmo significado ou com significado similar ao de "cidade média".

De acordo com Correia (2007), a noção ou possível conceito de cidade média deriva de uma construção intelectual, e enquanto tal, inserida em determinado conceito histórico e geográfico. Com a substituição do padrão demográfico caracterizado por cidades de diversos tamanhos e pouco articuladas por uma rede urbana mais articulada e dotada de centros mais diferenciados entre si, pode-se, então falar em cidades médias.

Os primeiros conceitos de cidade média levavam em conta critérios estritamente quantitativos, em especial a dimensão populacional, o limite populacional mínimo para uma cidade ser considerada média variava de acordo com os autores e com a realidade de cada país. De acordo com Amorim Filho e Serra (2001), não existia uma idéia consensual do que

Geo UERJ - Ano 15, n⿳⺈.24, v. 1, $1^{\circ}$ semestre de 2013 p. 228-255

ISSN: 1415-7543E-ISSN: 1981-9021

http://www.e-publicacoes.uerj.br/index.php/geouerj 
seriam as cidades médias, e o critério demográfico é capaz apenas de identificar o grupo ou a faixa que pode conter as cidades médias.

Um segundo critério bastante utilizado pela literatura para classificar as cidades médias é sua funcionalidade, sua centralidade urbana e administrativa, bem como seu papel no desenvolvimento regional. As principais funções dessas cidades seria reduzir os movimentos migratórios através da ampliação da oferta de empregos e serviços à população do meio rural e das cidades menores no seu entorno. (ESTEBAN y LÓPEZ, 1989).

Os primeiros estudos realizados sobre cidades médias no Brasil utilizavam como parâmetros de definição das cidades médias, aspectos quantitativos, relacionados diretamente com a dimensão demográfica associada com uma lógica funcional.

$\mathrm{Na}$ época, foram elaborados alguns atributos para a definição de quais cidades seriam consideradas cidades médias. Amorim Filho e Serra (2001) sintetizam esses atributos em: interações constantes com seu espaço regional subordinado e aglomerações superiores; tamanho demográfico suficiente para desempenhar o papel de centro de crescimento regional; capacidade de receber e fixar migrantes servindo como pontos de interrupção do movimento migratório na direção das grandes cidades; e diferenciação do espaço intra-urbano, com centro funcional e uma periferia dinâmica.

Para os autores, esses atributos refletem algumas das razões pelas quais a preocupação com as cidades médias tenham adquirido visibilidade e amplitude nas discussões e na política nos anos 1970, uma vez que, os principais objetivos das políticas urbanas implantadas no período buscavam: promover maior equilíbrio interurbano e inter-regional; interromper o fluxo migratório para as grandes cidades; e multiplicar os postos avançados da expansão do sistema capitalista. (AMORIM FILHO e SERRA, 2001, p. 9).

A política de desconcentração implementada nos anos 1970 e que resultou em certo fortalecimento das cidades médias foi interrompida na década de 1980, em grande parte como resultado da crise instalada na economia do país, a partir da qual, a política governamental passa a priorizar a estabilidade monetária em detrimento da continuidade do projeto de desenvolvimento econômico regional.

Essas mudanças, portanto, não afetam apenas as áreas mais dinâmicas do país, causam impactos também nas demais regiões. A partir de meados dos anos 1980 e, principalmente na década de 1990, a crise e a instabilidade econômica interromperam as transformações que vinham ocorrendo na distribuição regional da indústria, fazendo com que o processo fosse de 
certa forma, revertido; ou seja, o processo de desconcentração foi paralisado, voltando a produção a se reconcentrar nas áreas mais dinâmicas do Centro-Sul do país.

Nesse sentido, Araújo (2000) afirma que as mudanças políticas e econômicas ocorridas no âmbito nacional tendem a romper a prioridade dada à montagem de uma base econômica que ia lentamente desconcentrando atividades para as regiões periféricas. Esse fenômeno torna-se mais grave quando se verifica a guerra fiscal entre os Estados para consolidar alguns pontos de dinamismo em suas áreas de atuação. As regiões transformam-se em plataformas para atrair investimentos e a ação pública passa a subsidiar custos de implantação. Brandão vai mais além ao afirmar que

Estabelece-se um verdadeiro certame de localização, em uma interminável contenda por estabelecer uma posição máxima na gradação de ofertas tributárias, de terras e infra-estrutura etc. O receptor das benesses (a grande empresa) é quem determina o final do torneio e define o vitorioso da guerra entre lugares. (BRANDÃO, 2007, p. 49)

Essa opção dos grupos econômicos trabalharem apenas nos espaços mais dinâmicos, sem que o Estado contrabalance essa tendência, faz com que o recorte macrorregional tornese insuficiente para explicar a diferença entre os vários espaços, de modo que cada grande região tem pedaços competitivos e espaços em abandono. “[...] Onde o capital produtivo não constitui o setor hegemônico da economia, o Estado não se obriga, necessariamente, a viabilizar as condições de produção e reprodução do capital e da força de trabalho." (CLEMENTINO, 1995, p. 30).

As possíveis explicações para estas mudanças estão relacionadas às já mencionadas alterações na condução da política econômica em nível nacional e ao movimento de reconcentração, às mudanças tecnológicas e à reestruturação produtiva, as quais alteraram os requisitos locais de atração das indústrias, principalmente daquelas atividades mais intensivas em conhecimento.

Entretanto, as mudanças ocorridas na economia mundial, dentre as quais destacamos o acentuado processo de internacionalização dos fluxos de capital e de mercadorias, com seus consequentes impactos na organização da produção, parecem ter impulsionado novamente o interesse pelas chamadas cidades médias, ao mesmo tempo em que impuseram reformulações nos seus papéis.

Amorim Filho e Serra, (2001) destacam duas vertentes: na primeira, o fortalecimento do papel de articulação e intermediação desempenhado pelas cidades médias como

Geo UERJ - Ano 15, no. 24, v. 1, $1^{\circ}$ semestre de 2013 p. 228-255

ISSN: 1415-7543E-ISSN: 1981-9021

http://www.e-publicacoes.uerj.br/index.php/geouerj 
fundamental para a implantação, o desenvolvimento e a expansão de eixos e corredores de transportes e comunicações, de redes de todo tipo e de redes especiais, tais como as das tecnopóles; e na segunda incluem-se características até então não contempladas nos estudos e projetos das cidades médias, como qualidade de vida, questões relativas a patrimônio e identidade, bem como aquelas referentes a valores, motivações e preferências sociais e individuais, fortemente correlacionadas com o direcionamento de fluxos turísticos de massas humanas cada vez maiores.

É nesse novo contexto econômico da globalização e das reconfigurações territoriais provovadas pela reestruturação produtiva que se apresentam, que uma gama de autores tem proposto a utilização do termo cidade intermédia ou cidade intermediária, em cujo escopo está embutido critérios de natureza qualitativa, dentre eles a idéia de um espaço de relações estruturados em nós e fluxos. O conceito de cidade intermédia/intermediária introduzido pelo francês Michel Gault no final dos anos 1980 "valoriza os critérios de natureza qualitativa em detrimento da excessiva rigidez demográfica." (AVELINO, 1999, p. 466).

Para além de uma mudança nominal, Ferrão et. al. destaca que o novo conceito é uma concepção mais rica e alargada que realça os aspetos relacionais.

O duplo sentido de intermédio/intermediário sugere a ideia de um espaço de relações (entre cidades e entre cidades e regiões), estruturados em nós e fluxos, onde a 'cidade intermédia' é (ou pode e deve ser) um medianeiro, um ponto de encontro e de passagem obrigatória. (FERRÃO, et al, 1994, p. 1128).

Esteban y López (1989) destacam que as cidades médias tem um papel muito importante em relação ao seu entorno no que se refere a reabilitação econômica e social do espaço rural com a finalidade de evitar seu despovoamento. Ou seja, a cidade média potencialmente ofereceria empregos, equipamentos e serviços demandados por sua área de influência.

Importante destacar, que no Brasil a rede urbana é desigual e diferenciada, inclusive no que se refere à concentração das metrópoles e das grandes cidades nas regiões Sudeste e Sul do país, o mesmo ocorrendo com as cidades médias.

Em estudo recente sobre cidades médias Castello Branco afirma:

[...] como em todo estudo sobre a rede urbana brasileira, apresenta grande desigualdade na distribuição espacial das cidades aqui consideradas como de nível médio e também uma grande diversidade interna dos atributos selecionados para análise. (CASTELLO BRANCO, 2006, p. 268).

Geo UERJ - Ano 15, no . 24, v. 1, $1^{\circ}$ semestre de 2013 p. 228-255

ISSN: 1415-7543E-ISSN: 1981-9021

http://www.e-publicacoes.uerj.br/index.php/geouerj 
Nesse sentido Pereira (2007) afirma que os estudos sobre as cidades médias devem estar calcados numa concepção, em rede, da cidade e da região, numa perspectiva que priorize, mais que a dimensão demográfica, a forma como a cidade média se articula com o sistema urbano.

No Brasil, a aceleração do processo de urbanização a partir dos anos 1960, bem como a consequente reorganização do sistema urbano se deu sob os impactos da industrialização com todas as características de um país periférico.

A industrialização, ou melhor, a acumulação capitalista ancorada na produção industrial, ao ir redefinindo o modo de inserção das diversas áreas regionais no quadro da divisão do trabalho, transforma a estrutura social e reestrutura a rede urbana pré-existente, integrando-a e redefinindo a posição e a função dos diferentes nódulos do sistema urbano brasileiro. (FARIA, 1978, p. 99-100).

Na região Nordeste, o processo de urbanização foi lento e atomizado, nas palavras de Cano "[uma] urbanização geográfica e economicamente dispersa, constituída principalmente por suas nove capitais regionais e cerca de duas dezenas de cidades de porte médio, muitas delas interiorizadas" (1989, p. 68).

Em pesquisa recente, Pontes $(2006)^{5}$ identificou 21 cidades médias na região Nordeste, são elas: Caxias, Imperatriz e Timon (MA); Parnaíba (PI); Sobral e Juazeiro do Norte (CE); Mossoró (RN); Campina Grande (PB); Caruaru, Garanhuns, Petrolina e Vitória de Santo Antão (PE); Arapiraca (AL); Alagoinha, Barreiras, Feira de Santana, Ilhéus, Itabuna, Jequié, Juazeiro e Vitória da Conquista (BA).

Apesar das especificidades de cada cidade apontadas no estudo, a autora apresenta algumas características comuns às cidades médias nordestinas, entre as quais destacamos: tendência à migração campo-cidade em virtude da estagnação de atividades primárias em várias áreas do Nordeste; progressiva terciarizição da economia com a presença de estruturas heterogêneas; as mudanças e modernizações ocorridas no período recente não foram suficientes para proporcionar melhores condições de vida à população nordestina; o desemprego e a pobreza ainda persistem nas cidades médias estudadas; verificou-se ainda, graves problemas pertinentes à saúde, à educação, ao saneamento básico, aos déficits ocupacionais e ao transporte urbano. (PONTES, 2006).

O último estudo do IBGE sobre cidades - REGIC, também destaca a existência de duas dinâmicas distintas na rede urbana nordestina: uma do interior, outra do litoral Geo UERJ - Ano 15, nº 24, v. 1, $1^{\circ}$ semestre de 2013 p. 228-255

ISSN: 1415-7543E-ISSN: 1981-9021

http://www.e-publicacoes.uerj.br/index.php/geouerj 
especificamente das capitais, tanto para comércio como para serviços.

A rede urbana dessa região [Nordeste] é fortemente comandada pelas capitais dos estados, apoiada em poucos centros do interior, como os de Campina Grande (PB), Juazeiro-Petrolina (BA-PE), Caruaru (PE), Mossoró (RN), Juazeiro do Norte-CratoBarbalha (CE), Feira de Santana, Ilhéus-Itabuna e Vitória da Conquista (BA). (IBGE, 2008, P.143).

É a partir dessa perspectiva que buscamos compreender as funções urbanas de Pau dos Ferros-RN, Sousa e Cajazeiras-PB no desenvolvimento regional e de ordenação do território e o papel que elas desempenham nas suas respectivas regiões de influência que perpassa a raia divisória RN-PB-CE. À priori essas funções seriam oferecer empregos suficientes para acolher a população rural do entorno e absorver a população dos núcleos urbanos saturados e facilitar as condições de vida (educação, saúde, lazer e moradia).

De acordo com Pereira (2007), um estudo que se propõe a pensar a cidade intermédia em sua relação com a região implica uma análise das relações, fluxos e processos que condicionam a produção da cidade bem como seu papel regional.

Nesse sentido pautamos nossa pesquisa não apenas na importância econômica das cidades de Pau dos Ferros-RN, Cajazeiras e Sousa-PB ou de suas funções urbanas para os seus respectivos estados, mas também nos propomos a discutir como essas cidades se relacionam com suas regiões de influencia e com outros centros.

Para a construção deste artigo, utilizamos os dados do REGIC (2008), para os centros em epígrafe, inclusive os dados agregados constantes no seu banco de dados que permite verificar informações referentes à economia, à gestão do território e aos relacionamentos existentes entre as cidades e suas áreas de influência.

\section{As cidades (inter) médias no desenvolvimento regional: um estudo das cidades de Pau dos Ferros-RN, Cajazeiras e Sousa-PB.}

Os temas ligados às cidades médias constituem a grande contribuição da década de 1970 em termos de planejamento urbano-regional, em especial na Europa do pós-guerra "quando se manifesta a necessidade de uma nova planificação: o aménagement du territoire." (AMORIM FILHO e SERRA, 2001, p. 5). 
Foi nesse ambiente que se reconheceu as potencialidades das cidades médias e a sua valorização no domínio das políticas regionais. Calcados na teoria da localização, os teóricos funcionalistas acreditavam que as cidades médias eram:

as únicas cuja dimensão garantia a ocorrência de economia externas e às quais se associavam hinterlands suficientemente vastos para permitirem a difusão alargada dos benefícios da concentração de atividades. [...] Dessa forma, as cidades médias cumpririam uma dupla função: colocava-se ao serviço do propósito de reequilíbrio do território e, prosseguia o modelo de desenvolvimento polarizado. (FERRÃO et al, 1994, p. 1125)

Com o novo cenário econômico, surge a necessidade de reavaliar o atributo dos lugares e obriga a uma transformação das estratégias e práticas do planejamento. Ferrão et al (1994) propõe um novo olhar sobre as cidades de 'média dimensão', um olhar que valorize os aspectos qualitativos e reticulares, e para tal propõe o conceito de cidade 'intermédia'. Para o autor, o termo 'intermédia' valoriza os aspectos qualitativos, relacionais e estratégicos. A cidade intermédia é um espaço de relações entre cidades e entre cidades e regiões estruturadas em nós e fluxos, um ponto de encontro e passagem obrigatória.

Ferrão et al (1994) aponta ainda alguns fatores fundamentais para o dinamismo das cidades médias, tais como: boa rede de comunicações, nível de instrução e capacidade de investigação superior à média, ambiente residencial atrativo para os segmentos qualificados da população ativa, diversidade significativa de oportunidades de emprego, núcleo urbano central eficiente, forte apoio às atividades de âmbito cultural, empenho ativo das instituições públicas na vida da cidade.

É com base nesse 'novo olhar' que nos propomos a estudar os centros sub-regionais de Pau dos Ferros-RN, Cajazeiras e Sousa-PB e seu papel no desenvolvimento regional.

Os centros sub-regionais em estudo estão localizados na região de fronteira entre Estados do Rio Grande do Norte, do Ceará e da Paraíba, distantes das capitais de seus respectivos estados em média 400km; encravados num 'triângulo' formado pelas antigas Capitais Regionais ${ }^{6}$ de Mossoró-RN, Campina Grande-PB e Juazeiro do Norte-CE. Pau dos Ferros-RN, Cajazeiras e Sousa-PB estão, portanto, localizados na chamada "rede urbana nordestina interiorizada"7 conforme mapa 1.

Reforçamos ainda que a localização de Pau dos Ferros-RN, Cajazeiras e Souza-PB no entroncamento de rodovias federais ${ }^{8}$ tem sido significativa para sua posição na rede urbana dos seus respectivos Estados e para a confluência de uma quantidade de população de outros

Geo UERJ - Ano $15, \mathrm{n}^{\circ} .24$, v. 1, $1^{\circ}$ semestre de 2013 p. 228-255

ISSN: 1415-7543E-ISSN: 1981-9021

http://www.e-publicacoes.uerj.br/index.php/geouerj 
municípios que vem a essas cidades em busca do comércio e/ou dos serviços públicos e privados lá oferecidos.

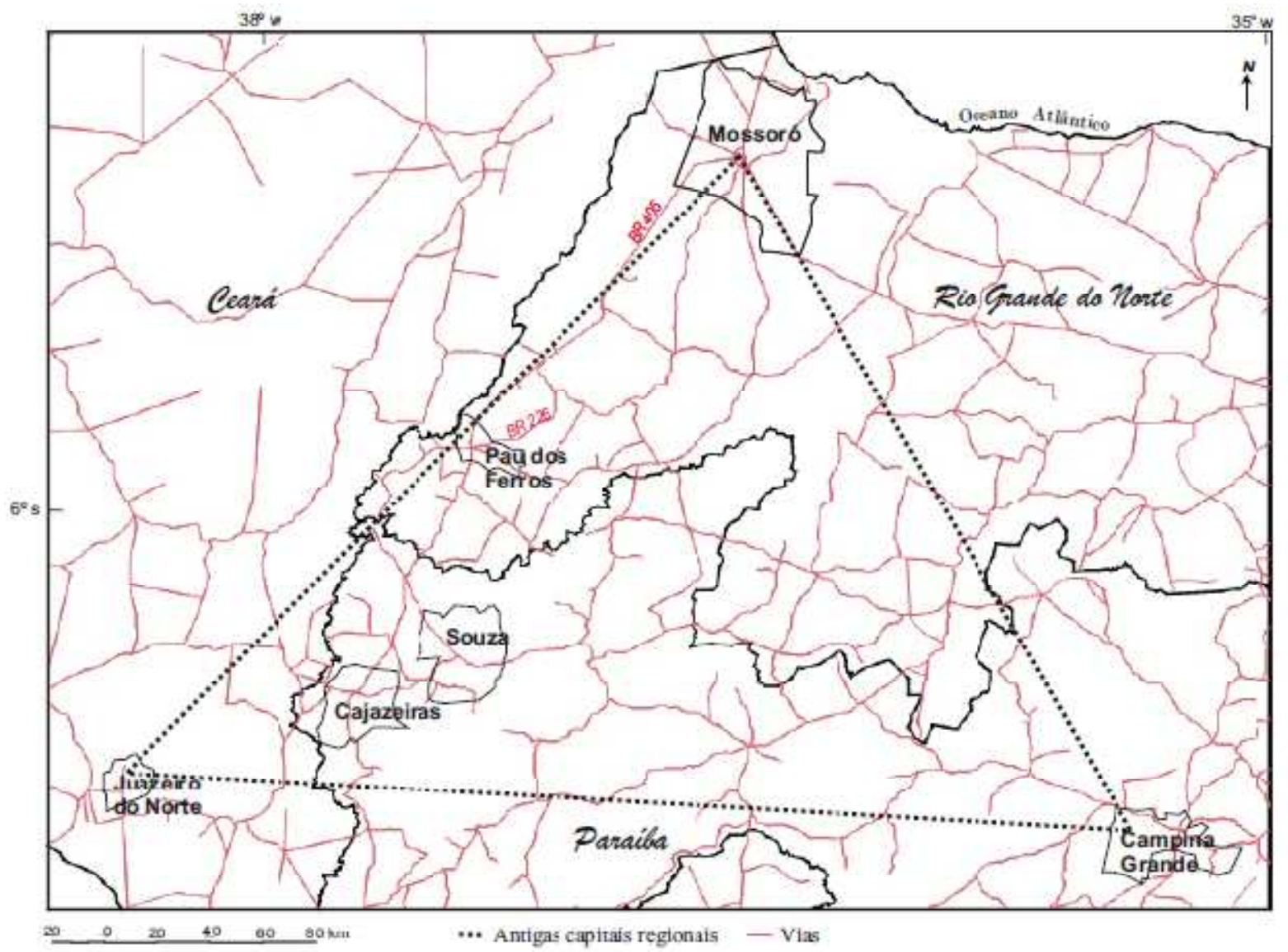

\section{MAPA 1 - Localização de Pau dos Ferros, Souza e Cajazeiras na rede urbana nordestina interiorizada.}

Fonte: Malha do IBGE 2000. Elaborado por Rosana França da Silva.

Partimos da hipótese de que a influencia dessas cidades ultrapassa seus respectivos Estados. Mesmo que a priori, Pau dos Ferros-RN, Cajazeiras e Sousa-PB não apresentem as características mais comuns de uma cidade média, sua localização fronteiriça reforça a sua influencia no desenvolvimento regional e reforça suas funções urbanas, chegando a munícipios dos vizinhos estados do Rio Grande do Norte, do Ceará e da Paraíba. É comum tratar essas cidades como 'cidades de fronteira' ou 'cidades fronteiriças'.

Diante das restrições político-administrativas vinculadas à noção de fronteiras internas (entre estados federados) para um estudo em que a dimensão espacial é norteadora do desenvolvimento regional, optamos por construir uma "raia" para denominar essa região.

Para a construção da noção de "raia de fronteira" nos apoiamos no trabalho de Passos (2009) que propõe a ideia de "raia divisória". Para este autor,

Geo UERJ - Ano 15, nº 24, v. 1, $1^{\circ}$ semestre de 2013 p. 228-255

ISSN: 1415-7543E-ISSN: 1981-9021

http://www.e-publicacoes.uerj.br/index.php/geouerj 
as fronteiras são raias, áreas de intergradação nas quais os processos se manifestam segundo uma lógica de descontinuidade objetiva da paisagem ou, ainda, segundo uma impermeabilidade muito acentuada entre as parcelas do território submetidas às definições e redefinições territoriais mais ou menos independentes. (PASSOS, 2009, p. 1)

A concepção da "raia divisória" sugere um espaço integrado que contempla a participação dos agentes e dos atores. O significado da "raia" extravasa sua vinculação aos sinônimos de linha ou limite no sentido de extensão ou como marcos rígidos entre o término de uma área e sob determinado domínio político-administrativo e o inicio de outra.

No Brasil, o estudo de "regiões fronteiriças" ou "raias fronteiriças" ainda é bastante incipiente, é mais comum utilizar como unidade de análise as unidades administrativas e as microrregiões propostas pelo IBGE.

Na Europa a utilização do termo 'raia' é mais comum, uma vez que a diversidade de culturas e suas territorialidades convivem ou colidem no quadro de um continente recortado por inúmeros países cujas dimensões são relativamente pequenas quando comparadas ao território brasileiro, por exemplo. A unificação dos mercados tem contribuído de forma significativa para a elaboração de políticas e programas de desenvolvimento local e regional da União Europeia.

\footnotetext{
Com a entrada de Portugal e da Espanha na Comunidade Europeia, em 1986, verificou-se um forte incremento das relações entre os países. Simultaneamente, o papel das regiões e das políticas regionais é valorizado com a consequente intensificação das relações entre regiões e, em particular, das regiões fronteiriças. (SOUZA, 2011, p. 25)
}

Distinguir fronteiras internas e fronteiras externas supõe considerar a dimensão política e as diferentes escalas de poder, já que se refere aos limites espaciais dentro dos quais o Estado pode exercer sua autoridade. "Um Estado soberano não está sujeito a nenhum outro poder, contrariamente a uma subunidade, que deve obediência a um nível superior de governo.” (HESPANHOL, 2011, p. 256)

Para a autora, no caso brasileiro, pode-se perceber que as fronteiras internas se constituíram ao longo do processo de ocupação que se deu da faixa litorânea em direção ao interior por meio dos diferentes interesses econômicos, políticos e geopolíticos das classes dominantes que procuravam expandir a sua influência, incorporando progressivamente várias áreas à economia capitalista.

Geo UERJ - Ano $15, \mathrm{n}^{\circ} .24$, v. 1, $1^{\circ}$ semestre de 2013 p. $228-255$

ISSN: 1415-7543E-ISSN: 1981-9021

http://www.e-publicacoes.uerj.br/index.php/geouerj 
No caso da Região Nordeste, enquanto a produção açucareira predominava no litoral, a ocupação do interior se dava inicialmente pela expansão da pecuária e depois em consórcio com o algodão. Além de seu importante papel histórico de ocupação do território e de suporte para a economia açucareira, a pecuária desempenhou outro, não menos relevante, na configuração do "complexo nordestino". 9

Os impactos desse sistema na rede urbana vêm ocorrendo desde o período colonial e tem rebatimentos na configuração da rede urbana nordestina ainda no período atual, a qual, como já explicado anteriormente apresenta uma dinâmica no litoral e outra no interior.

Passos (2006) identifica no Brasil algumas "raias divisórias" que necessitam de análise no sentido de revelar suas potencialidades culturais, sociais e econômicas com o objetivo de implantar planos de desenvolvimento regionais capazes de superar o estágio de periferia em que vivem tendo como mote a integração regional.

Na região Nordeste, Passos (2006), cita o Vale do Rio Grande, Oeste do Estado da Bahia, no qual ocorreram dois modelos de ocupação, um baseado na cultura dos sertanejos, seguindo um padrão tradicional e confinado e o outro 'dos sulistas' que ali implantaram a monocultura da soja a partir dos anos 1970.

Para a construção da Raia Divisória retomamos a configuração das antigas capitais regionais nordestinas, constituídas pelo Triângulo Mossoró-RN, Campina Grande-PB e Juazeiro do Norte-CE, onde as "cidades médias" Pau dos Ferros-RN, Cajazeiras-PB, SousaPB desempenham funções urbanas importantes ainda hoje.

A Raia Divisória Rio Grande do Norte-Paraíba-Ceará será composta pelos municípios que são 'cortados' pelas rodovias federais que perpassam o interior dos estados do Rio Grande do Norte, Paraíba e Ceará (BRs 405, 226, 230 e 116) e/ou que estão no interior do ‘retângulo' formado pelo encontro dessas rodovias.

Pau dos Ferros-RN está localizado no interior do retângulo formado pelo encontro de quatro rodovias federais (BRs 405 e 226 no RN, BR 230 na PB e Br 116 no CE), mais precisamente na intersecção das BRs 405 e 226; Cajazeiras e Sousa-PB estão no lado oposto do retângulo. Essa posição permite a essas cidades constituirem-se num entroncamento de vias de circulação e nó de tráfego, envolvendo pessoas, capitais, informações, mercadorias e serviços.

É importante ressaltar que na porção cearense da raia divisória $\mathrm{RN}-\mathrm{PB}-\mathrm{CE}$, não há centros sub-regionais, temos apenas 02 (dois) Centros de zona -Ico e Jaguaribe. 


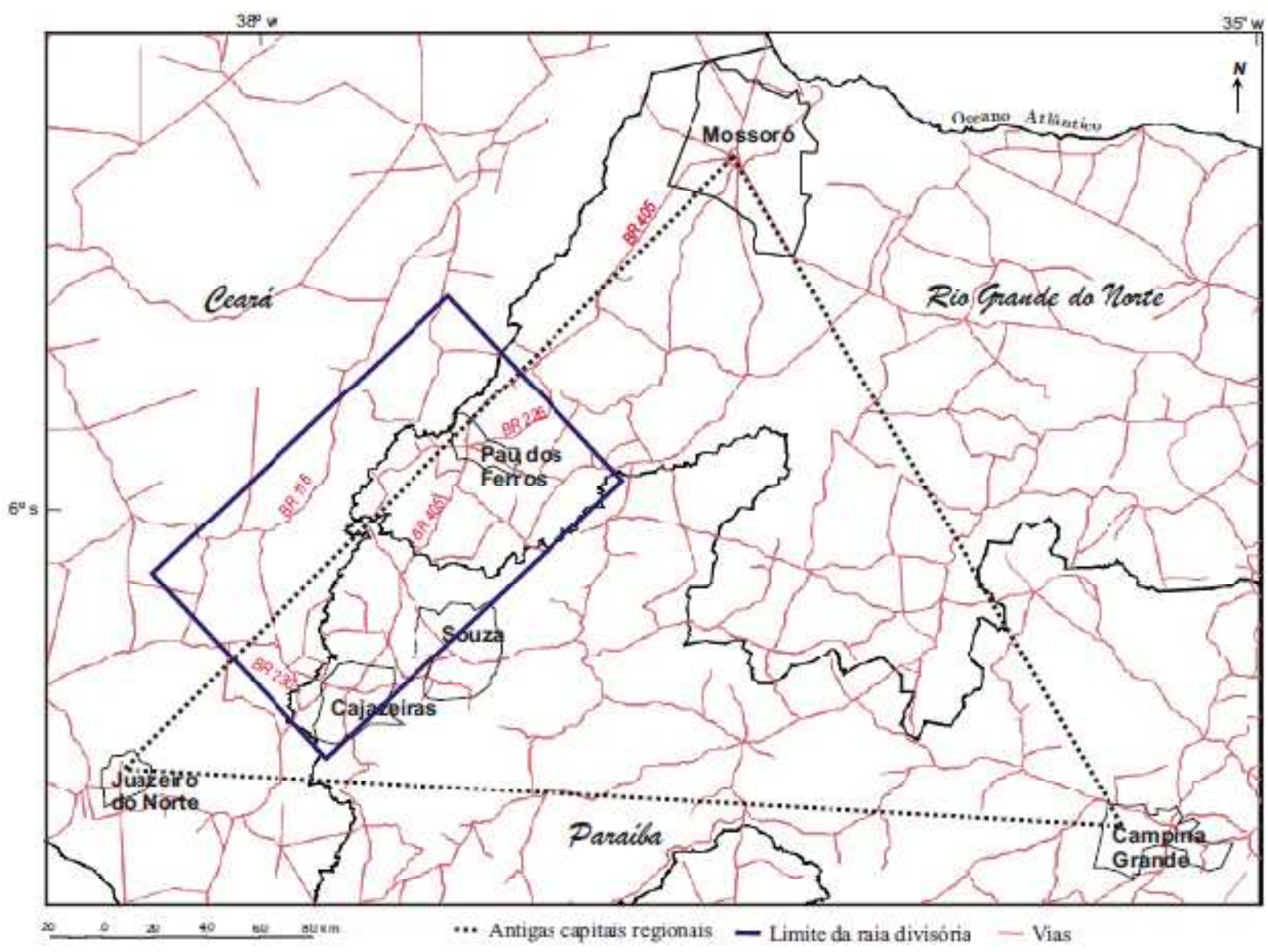

MAPA 2 - A Raia Divisória RN-PB-CE formada pelos entroncamentos viários Fonte: Malha do IBGE 2000. Elaborado por Rosana França da Silva.

Essa ausência de alguns níveis na hierarquia urbana é característica da rede urbana do Norte e Nordeste as quais apresentam "distribuições truncadas em que faltam níveis hierárquicos, apresentando um sistema primaz. [...] nesta região, as capitais tradicionalmente concentram a oferta de equipamentos e serviços e são poucas as opções de centro intermediário." (IBGE, 2008, p. 13).

O estudo do IBGE ressalta ainda que os centros existentes na rede urbana nordestina apesar de poucos, exercem forte polarização em suas áreas. O que nos leva a supor que por serem poucos possam ter suas áreas de influencias mais abrangentes.

Como a maioria das cidades do interior do Nordeste, as cidades de Pau dos Ferros-RN, Cajazeiras e Sousa-PB tiveram sua origem no movimento de circulação do capital mercantil; primeiro pela expansão da pecuária nordestina, através dos chamados caminhos do gado ${ }^{10}$; depois, com a expansão da produção algodoeira assumem posição importante para a comercialização do algodão do "Alto Oeste Potiguar", e do "Alto Sertão da Paraíba", seja em 
direção a Mossoró-RN, no caso de Pau dos Ferros, seja em direção a Campina Grande-PB, no caso de Cajazeiras e Sousa.

Com a crise algodoeira, as regiões sertanejas perdem seu principal produto agrícola, e, pelas próprias características de regiões semiáridas, com baixa incidência de chuvas e ocorrências cíclicas de seca, enfrentam diversos problemas. As precárias condições de vida fazem com que a população viva em constante migração, contribuindo para um sistema urbano desarticulado e heterogêneo.

De acordo com Clementino (1997), essa rede urbana irregular e dispersa se ampliou ainda mais com a facilidade para emancipação dos distritos após a Constituição de 1988 que estabeleceu critérios pouco rígidos para a criação de municípios, criou o Fundo de Participação dos Municípios (FPM) e não exigiu contrapartidas em serviços para a população local.

Numa região pobre, onde a agricultura de subsistência ainda predomina o fato de se não haver encontrado uma cultura que substitua o algodão, reduz a importância do setor primário; por outro lado, o aumento das transferências de receitas públicas institucionalizadas após a Constituição de 1988 faz com que o setor de comércio e serviços tenha sua participação relativa aumentada. Mais recentemente, com os chamados programas governamentais de "transferência de renda" comércio e serviços são dinamizados.

Em termos econômicos, assiste-se a predominância do setor terciário com participação no PIB acima de 70\% nos três municípios (73,19 em Cajazeiras-PB, 71,19 em Sousa e 79,8 em Pau dos Ferros).A participação setorial de cada atividade no Produto Interno Bruto de cada município, bem como a participação do setor público, pode ser visualizada na tabela 1 a seguir:

Tabela 1 - População e Produto Interno Bruto (Pau dos Ferros, Cajazeiras e Sousa 2005)

\begin{tabular}{|c|c|c|c|c|c|c|c|c|}
\hline Município & População & PIB Total & Agropecuário & Industrial & Serviços & Impostos & $\begin{array}{l}\text { Adm. } \\
\text { Pública }\end{array}$ & $\begin{array}{l}\text { Adm. } \\
\text { Publica/ } \\
\text { Serviços } \\
\end{array}$ \\
\hline Cajazeiras & 56051 & 229199,72 & 3822,29 & 30733,64 & 167747,48 & 26892,31 & 68966,88 & 41,11 \\
\hline Sousa & 63783 & 232508,43 & 13723,98 & 33619,74 & 165597,65 & 19567,06 & 80522,36 & 48,62 \\
\hline $\begin{array}{l}\text { Pau dos } \\
\text { Ferros }\end{array}$ & 26728 & 99964,65 & 3673,25 & 8646,82 & 79777,13 & 7867,44 & 36450,32 & 45,69 \\
\hline
\end{tabular}

Fonte: IBGE (2008) - Banco de Dados.

Elaboração das autoras.

Geo UERJ - Ano 15, n⿳. 24, v. 1, $1^{\circ}$ semestre de 2013 p. 228-255

ISSN: 1415-7543E-ISSN: 1981-9021

http://www.e-publicacoes.uerj.br/index.php/geouerj 
Importante salientar que a participação do setor público nos serviços também é bastante significativa nas cidades estudadas, sempre acima de $40 \%$, o que confirma a importância da presença do Estado na região; presença que tem se ampliado na última década com a interiorização do ensino superior nos níveis médio e técnico, com a implantação e/ou ampliação dos Institutos Federais e, no nível superior com a ampliação dos cursos da Universidade Federal de Campina Grande (UFCG) no caso de Cajazeiras e Sousa e com a ampliação dos cursos da Universidade do Estado do Rio Grande do Norte (UERN) e a implementação de um Campus da Universidade Federal do Semi-Árido (UFERSA) no caso de Pau dos Ferros.

Salientamos que o aumento do investimento do setor público na interiorização do ensino superior tem sido acompanhado por instituições privadas que também estão se instalando nessas localidades. O mesmo acontecendo com a área de saúde privada que também tem se expandido no período recente. Steinberger e Bruna (2001) ressaltam a relevância das cidades médias no sentido das mesmas serem elos de ligação entre os espaços urbano e regional e entre os interesses públicos e privados.

Além da presença significativa do setor terciário, e dentro deste, da administração pública nos municípios citados, retomaremos os "elementos essenciais" levantados por Correia (2007), para a definição das cidades médias, e utilizados pelo próprio IBGE na definição dos centros, que hierarquizam a rede urbana brasileira, dentre os quais se destaca a função de gestão do território. Para o IBGE,

Centro de gestão do território [...] é aquela cidade onde se localizam, de um lado, os diversos órgãos do Estado e, de outro, as sedes das empresas cujas decisões afetam direta ou indiretamente um dado espaço que passa a ficar sob o controle da cidade através das empresas nela sediadas. (CORRÊA, 2005 apud IBGE, 2008, p. 131).

Na tabela abaixo, podemos visualizar os níveis de gestão quantificados pelo IBGE $^{11}$, para os municípios selecionados.

Tabela 2 - Níveis dos centros de gestão, segundo o REGIC - 2007

\begin{tabular}{l|l|l|r}
\hline \hline Municípios & Gestão Territorial $^{\mathbf{1}}$ & Gestão Federal $^{2}$ & Gestão Empresarial $^{\mathbf{3}}$ \\
\hline \hline Cajazeiras & 5 & 6 & 6 \\
\hline Sousa & 5 & 6 & 7 \\
\hline
\end{tabular}

Geo UERJ - Ano 15, n⿳0.24, v. 1, $1^{\circ}$ semestre de 2013 p. 228-255

ISSN: 1415-7543E-ISSN: 1981-9021

http://www.e-publicacoes.uerj.br/index.php/geouerj 
${ }^{1}$ Intervalo de 1 a 6 - quanto mais próximo de 1 melhor a situação;

${ }^{2}$ Intervalo de 1 a 8 - quanto mais próximo de 1 melhor a situação;

${ }^{3}$ Intervalo de 1 a 8 - quanto mais próximo de 1 melhor a situação;

Fonte: IBGE (2008) - Banco de Dados.

Elaboração da autora.

Por esse parâmetro os centros sub-regionais pouco se diferenciam, todos obtém o nível 5 em gestão territorial, e nível 6 em gestão federal, apenas em termos de gestão empresarial Cajazeiras-PB aparece relativamente melhor, o que nos leva a deduzir que a 'elite empreendedora' ainda é frágil nos municípios em estudo. Em Pau dos Ferros-RN e Sousa-PB, a gestão empresarial é muito frágil, do que podemos inferir que apesar do destaque nas atividades de comércio nos municípios, o setor ainda não tem dinâmica empresarial expressiva.

Outra variável considerada na classificação dos centros é a intensidade de relacionamentos estabelecidos com as demais cidades da região e com outros centros. Essa variável corrobora a importância da prestação de serviços na área de educação e saúde para suas regiões. Os relacionamentos de cursos e os relacionamentos de saúde estão entre os três mais citados nas cidades estudadas, com o máximo de 47 citações no caso do relacionamento de cursos em Cajazeiras e 37 citações no caso do relacionamento de saúde em Sousa. (IBGE, 2008).

Acreditamos que esse destaque assumido pelos centros sub-regionais nos relacionamentos com outras cidades deve-se em grande parte a sua localização às margens das rodovias federais (BRs 405, 226 e 230) e a sua localização na raia divisória RN-PB-CE. Essa especificidade junto com a própria distância das capitais de seus respectivos estados (Natal e João Pessoa) e das capitais regionais (Mossoró, Juazeiro do Norte e Campina Grande) faz com que haja grande convergência de pessoas em busca dos mais variados produtos e serviços em Pau dos Ferros, Cajazeiras e Sousa.

A intensidade de relacionamentos das três cidades em estudo pode ser observada no gráfico abaixo: 


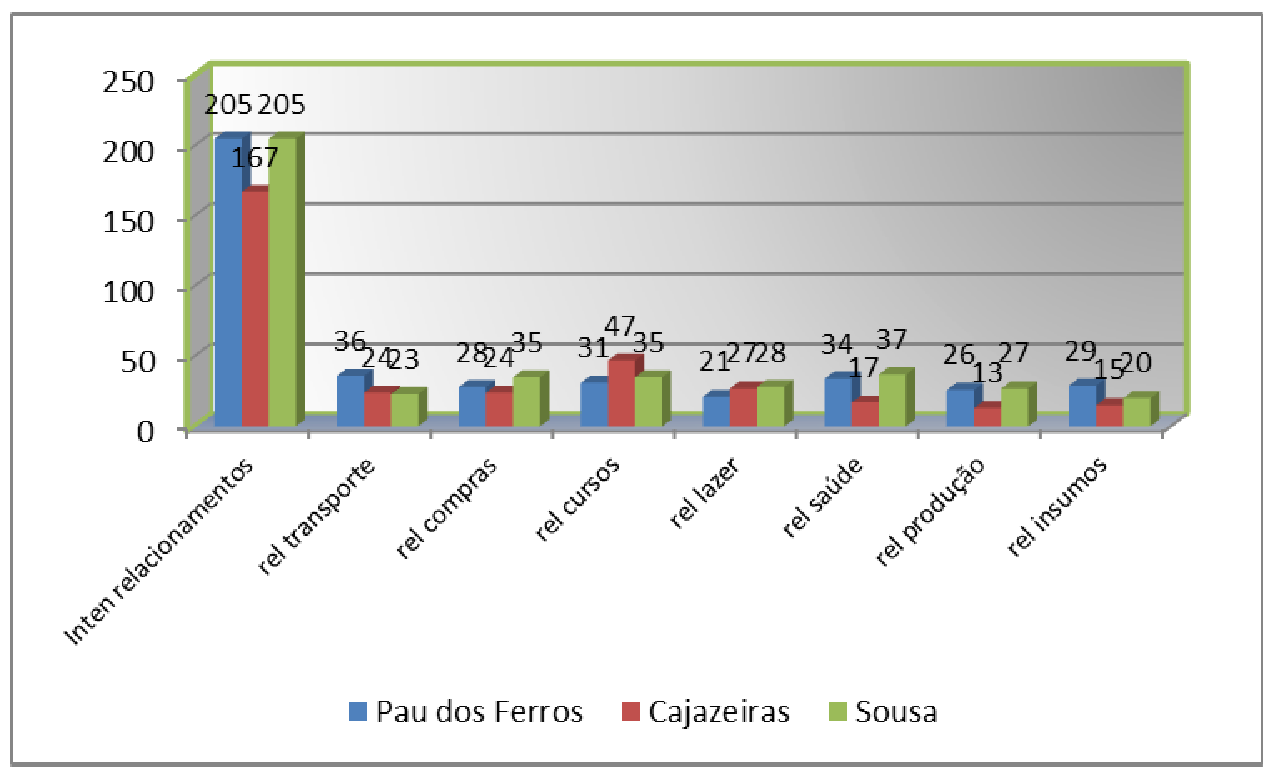

Gráfico 1 - Intensidades de relacionamentos (municípios selecionados - 2007) Fonte: IBGE (2008) - Banco de Dados. Elaboração das autoras.

Com os dados referentes aos relacionamentos, procuramos saber quais são os municípios que enviam diariamente pessoas para Pau dos Ferros, Cajazeiras e Sousa em busca dos serviços ofertados. A análise dos microdados do REGIC, em especial a variável 'ligações entre cidades', permitiu delinear suas áreas de influencia e esclarecer a articulação das redes no território.

No REGIC foram investigadas as ligações de transportes coletivos e os principais destinos dos moradores dos municípios para obter produtos e serviços (cursar ensino superior, comprar roupas, calçados, ou frequentar shoppings e hipermercados, usar aeroporto, buscar serviços de saúde e para atividades de lazer). Foram investigados ainda a origem dos insumos e o primeiro destino da produção dos três principais produtos agrícolas ${ }^{12}$. Esses itens foram agregados em 07 variáveis: compras, cursos, lazer, saúde, transporte, insumos e destino da produção agropecuária.

$\mathrm{Na}$ definição da área de influencia das cidades em estudo consideramos todos osmunicípios que demandaram pelo menos 01 dos itens considerados acima. Como resultado, temos: na área de influencia de Pau dos Ferros 45 municípios (39 do Rio Grande do Norte, 02 da Paraíba e 04 do Ceará); na área de influencia de Cajazeiras 51 municípios (38 da Paraíba, 04 do Rio Grande do Norte e 09 do Ceará) e; na área de influencia de Sousa 50 municípios (48 da Paraíba e 08 do Rio Grande do Norte),conforme quadro a seguir. 
DOI: $10.12957 /$ geouerj.2013.6915

Quadro 1 - Municípios que mantem relações com Pau dos $\operatorname{Ferros}(\mathrm{RN})$, Cajazeiras e Sousa(PB) - REGIC 2007

Geo UERJ - Ano $15, \mathrm{n}^{\circ} .24$, v. $1,1^{\circ}$ semestre de 2013 p. 228-255

ISSN: 1415-7543E-ISSN: 1981-9021

http://www.e-publicacoes.uerj.br/index.php/geouerj 


\begin{tabular}{|c|c|c|}
\hline Pau dos Ferros & Cajazeiras & Sousa \\
\hline Água Nova-RN & José da Penha-RN & Alexandria-RN \\
\hline Alexandria-RN & Luís Gomes-RN & José da Penha-RN \\
\hline Almino Afonso-RN & Major Sales-RN & $\begin{array}{l}\text { Luís Gomes-RN } \\
\text { Major Sales-RN }\end{array}$ \\
\hline Antônio Martins-RN & Paraná-RN & Paraná-RN \\
\hline Apodi-RN & Aguiar-PB & Rafael Fernandes-RN \\
\hline Caraúbas-RN & Aparecida-PB & Riacho de Santana-RN \\
\hline Coronel João Pessoa-RN & Bernardino Batista-PB & Aparecida-PB \\
\hline Doutor Severiano-RN & Bom Jesus-PB & Bernardino Batista-PB \\
\hline Encanto-RN & Bonito de Santa Fé-PB & Bom Jesus-PB \\
\hline Felipe Guerra-RN & Cachoeira dos Índios-PB & Bom Sucesso-PB \\
\hline Francisco Dantas-RN & Carrapateira-PB & Bonito de Santa Fé-PB \\
\hline Frutuoso Gomes-RN & Conceição-PB & Brejo do Cruz-PB \\
\hline Itaú-RN & Ibiara-PB & Brejo dos Santos-PB \\
\hline Jardim de Piranhas-RN & Jericó-PB & Cachoeira dos Índios-PB \\
\hline João Dias-RN & Lagoa-PB & Cajazeirinhas-PB \\
\hline José da Penha-RN & Lastro-PB & Carrapateira-PB \\
\hline Lucrécia-RN & Marizópolis-PB & Conceição-PB \\
\hline Luís Gomes-RN & Mato Grosso-PB & Coremas-PB \\
\hline Major Sales-RN & Monte Horebe-PB & Jericó-PB \\
\hline Marcelino Vieira-RN & Nazarezinho-PB & Lagoa-PB \\
\hline Martins-RN & Pocinhos-PB & Lastro-PB \\
\hline Paraná-RN & Poço Dantas-PB & Malta-PB \\
\hline Patú-RN & Poço de José de Moura-PB & Marizópolis-PB \\
\hline Pilões-RN & Pombal-PB & Mato Grosso-PB \\
\hline Portalegre-RN & Santa Cruz-PB & Monte Horebe-PB \\
\hline Rafael Fernandes-RN & Santa Helena-PB & Nazarezinho-PB \\
\hline Rafael Godeiro-RN & Santa Inês-PB & Paulista-PB \\
\hline Riacho da Cruz-RN & Santana de Mangueira-PB & Pocinhos-PB \\
\hline Riacho de Santana-RN & Santarém-PB & Poço Dantas-PB \\
\hline Rodolfo Fernandes-RN & São Bentinho-PB & Poço de José de Moura-PB \\
\hline São Francisco do Oeste-RN & São Bento-PB & Pombal-PB \\
\hline São Miguel-RN & São Domingos de Pombal-PB & Puxinanã-PB \\
\hline Serrinha dos Pintos-RN & São Francisco-PB & Riacho dos Cavalos-PB \\
\hline Severiano Melo-RN & São João do Rio do Peixe-PB & Santa Cruz-PB \\
\hline Taboleiro Grande-RN & São José da Lagoa Tapada-PB & Santa Helena-PB \\
\hline Tenente Ananias-RN & São José de Caiana-PB & Santa Luzia-PB \\
\hline Umarizal-RN & São José de Piranhas-PB & Santa Teresinha-PB \\
\hline Venha-Ver-RN & Serra Grande-PB & Santarém-PB \\
\hline Viçosa-RN & Soledade-PB & São Bentinho-PB \\
\hline Bom Sucesso-PB & Triunfo-PB & São Bento-PB \\
\hline $\begin{array}{l}\text { São José do Brejo do Cruz-PB } \\
\text { Ererê-CE }\end{array}$ & Uiraúna-PB & São Domingos de Pombal-PB \\
\hline Iracema-CE & Aurora-CE & São Francisco-PB \\
\hline Pereiro-CE & Baixio-CE & São João do Rio do Peixe-PB \\
\hline Potiretama-CE & Barro-CE & São José da Lagoa Tapada-PB \\
\hline & $\begin{array}{l}\text { Brejo Santo-CE } \\
\text { Ipaumirim-CE }\end{array}$ & São José de Piranhas-PB \\
\hline
\end{tabular}

Fonte: IBGE (2008). Elaboração das autoras.

Conforme podemos observar no quadro acima, a área de influencia das cidades

Geo UERJ - Ano 15, no. 24, v. 1, $1^{\circ}$ semestre de 2013 p. 228-255

ISSN: 1415-7543E-ISSN: 1981-9021

http://www.e-publicacoes.uerj.br/index.php/geouerj 
estudadas é bastante ampla (101 municípios) e ultrapassa as fronteiras estaduais, no caso de Pau dos Ferros-RN e Cajazeiras-PB a polarização se estende a municípios dos três estados, cobrindo uma extensa área do interior nordestino o que corrobora a importância do estudo da raia divisória RN-PB-CE e a necessidade de aprofundá-lo em outras pesquisas.

Do quadro também é possível inferir que as áreas de influencia de Cajazeiras e Sousa se intercalam em mais da metade dos municípios. Em menor grau percebe-se a intercalação das áreas das três cidades; são quatro municípios, ambos do Rio Grande do Norte: Luís Gomes e Paraná localizados na fronteira com a Paraíba e, Major Sales e José da Penha, localizados à margem da BR 405, a menos de $20 \mathrm{~km}$ da fronteira com a Paraíba.

Somadas as populações dos 101 municípios, com a inclusão dos municípios estudados, tínhamos, em 2010, nessa área, mais de um milhão de habitantes, mais precisamente, 1.074 .588 habitantes, dos quais 670.325 (62,38) viviam em áreas urbanas. (IBGE, 2010). Esse quantitativo corrobora a importância das três cidades estudadas na rede urbana nordestina interiorizada e a necessidade de se desenvolver estudos mais aprofundados na região que busque soluções para os diversos problemas existentes.

O banco de dados do REGIC nos possibilitou ainda verificar para quantos produtos e /ou serviços o centro foi citado como local de demanda pelos municípios. Tomando por base as sete variáveis escolhidas (cursos, compras, lazer, transporte, saúde, insumos e venda da produção) estabelecemos a seguinte escala de relacionamentos: municípios que demandaram entre 1 e 2 variáveis (fraco); municípios que demandaram entre 3 e 5 variáveis (médio); e municípios que demandaram entre 6 e 7 variáveis (forte). O gráfico abaixo mostra o resultado para as três cidades.

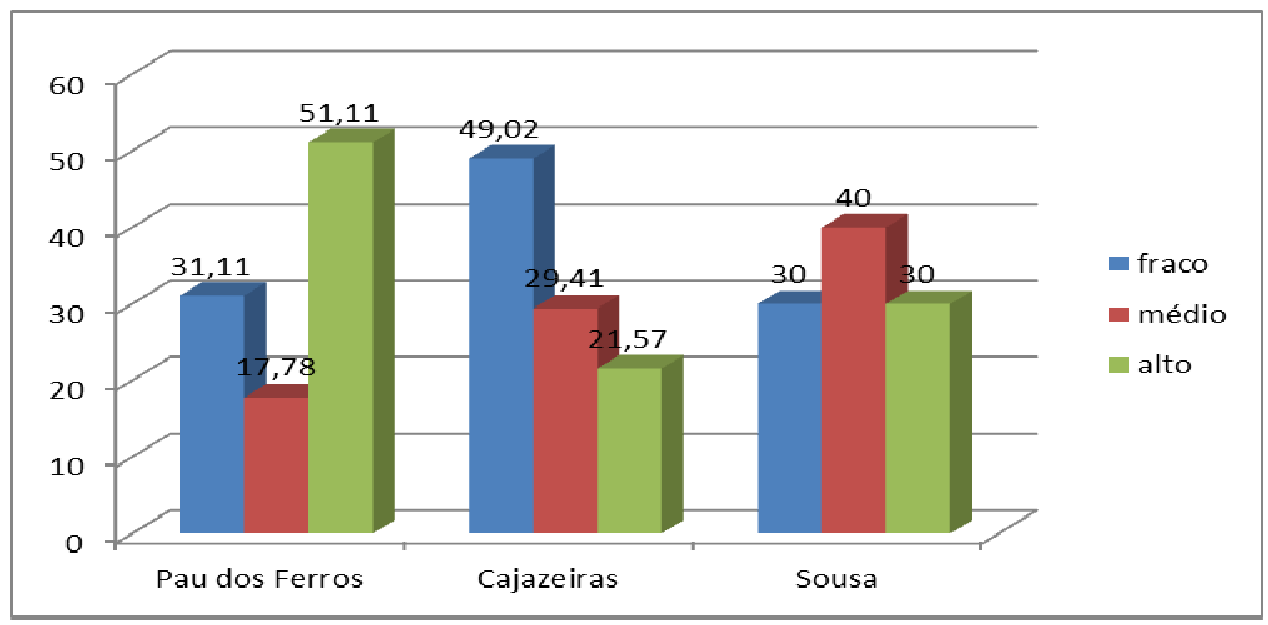

\section{Gráfico 2 - Grau de intensidade dos relacionamentos}

Geo UERJ - Ano $15, \mathrm{n}^{\circ} .24$, v. 1, $1^{\circ}$ semestre de 2013 p. $228-255$

ISSN: 1415-7543E-ISSN: 1981-9021

http://www.e-publicacoes.uerj.br/index.php/geouerj 
Fonte: IBGE (2008). Elaboração das autoras.

Do gráfico apresentado podemos inferir que os relacionamentos dos municípios com Pau dos Ferros são preponderantemente 'fortes', ou seja, mais da metade dos municípios busca em Pau dos Ferros seis ou sete dos serviços selecionados. Já quando observamos os graus de relacionamentos dos municípios com Cajazeiras e Sousa, a preponderância é dos graus 'fraco' e 'médio'.

Acreditamos que a proximidade de Cajazeiras e Sousa, bem como o fato de terem mais da metade da área de influencia conjunta leva a preponderância de graus de intensidade fraco e médio, ou seja, Cajazeiras e Sousa 'disputam' de certa forma a polarização no Alto Sertão da Paraíba; já em Pau dos Ferros a predominância do grau de intensidade forte, pode ser resultante da ausência de outros centros no 'Alto Oeste Potiguar' o que tende a aumentar a dependência dos municípios em relação aos serviços ofertados por Pau dos Ferros.

Verificamos ainda expansão da área de influencia para além dos limites estaduais de cada centro. Cajazeiras é a cidade que tem maior inserção em outros estados $(17,65 \%$ dos municípios da sua área de influencia estão no Ceará e 7,84\% estão no Rio Grande do Norte); já Pau dos Ferros é a que tem maior abrangência no próprio estado $(86,67 \%)$.

Em termos gerais, podemos afirmar que ao concentrar vínculos econômicos e estabelecer relações de transações comerciais com uma grande quantidade de municípios no entorno, Pau dos Ferros-RN, Cajazeiras e Sousa-PB se configuram como cidades (inter) médias, polarizando municípios vizinhos e ultrapassando as fronteiras dos seus respectivos estados.

\section{Considerações Finais}

O panorama aqui traçado visou dar um primeiro passo no sentido de uma investigação sobre a importância dos centros sub-regionais Pau dos Ferros, Cajazeiras e Souza para o desenvolvimento de suas respectivas regiões de influencia e o papel que ambos desempenham na rede urbana nordestina, em especial na área de fronteira dos estados do Rio Grande do Norte, Paraíba e Ceará, a qual denominamos Raia Divisória RN-PB-CE.

A existência de uma 'área de influencia conjunta' entre Sousa e Cajazeiras-PB era esperada, e inclusive já foi objeto de outros estudos. Destacamos aqui o estudo "Características e Tendências da Rede Urbana", realizado pelo IPEA (2002), no qual 
Sousa/Cajazeiras é tratado como um aglomerado urbano não metropolitano.

De acordo com o estudo do IPEA,

\begin{abstract}
Os dois núcleos urbanos apresentam ligações produtivas e comerciais, resultando em fluxos de dinheiro, mercadorias e pessoas. Tal complementaridade reforça o papel desse aglomerado urbano no sistema urbano do qual fazem parte, entre outros, São José de Piranhas, Lavras da Mangabeira, Bonito de Santa Fé e Conceição. [...] Embora Sousa se sobressaia em termos populacionais (77.911), Cajazeiras (51.396) apresenta uma maior participação da PEA nas atividades urbanas (74.1\%), principalmente na prestação de serviços e no comércio. As atividades administrativas (11.6\%) e industriais (15.3\%) também são mais representativas em Cajazeiras, devendo-se, estas ultimas, à expansão mais recente verificada no ramo calçadista. Está localizada em Sousa, por outro lado, grande parte da produção de redes do estado da Paraíba, o que justifica sua PEA industrial (14.2\%). (IPEA, 2002, p. 79).
\end{abstract}

O que podemos observar nesse estudo foi a ampliação da rede urbana de Pau dos Ferros-RN, ampliação que se deve em especial à interiorização da educação superior e à descentralização dos serviços de saúde, os quais tem contribuido para a atração de investimentos privados nas respectivas áreas, para a dinamização da economia da cidade e para a ampliação da sua área de influencia que ultrapassa os limites do Rio Grande do Norte para além das fronteiras do Rio Grande do Norte. Vale salientar que nem todos os rebatimentos dessa ampliação do ensino superior foram contabilizados no último REGIC. ${ }^{13}$ Dados das matrículas dos alunos nos cursos de graduação do Campus da UERN em Pau dos Ferros, no biênio 2010-2012, dão conta da expansão da área de influencia desta cidade para mais 07 (sete) municípios no Estado da Paraíba, ampliando assim a 'área de influencia conjunta' das três cidades. CAMEAM/UERN (2012).

Em termos gerais, o que se pode observar é que o comércio e os serviços tem uma participação relativa muito alta na composição do PIB das três cidades, reforçado pela participação do Estado, com destaque para a oferta dos serviços de educação, inclusive no nível superior e saúde. O destaque obtido nos relacionamentos com os três centros pelas variáveis 'cursos' e 'saúde' no último REGIC corrobora essa afirmação.

O estudo do IPEA "Caracterização e tendências da rede urbana" trata as "novas territorialidades' como "localidades que despontam pela grande potencialidade em termos de desenvolvimento de atividades voltadas para o turismo cultural, de lazer e o ecoturismo". (IPEA, 2002, p. 32) Ao mesmo tempo reforça a necessidade da especificidade local para que o 'diferente torne-se valor'. 
Consideramos a expansão do ensino superior, a partir da década de 2000, inicialmente na rede pública e posteriormente na rede privada, como um diferencial para a configuração urbano-regional de Pau dos Ferros-RN, Cajazeiras e Sousa-PB.

Atualmente em Pau dos Ferros, atuam na rede ensino superior além da UERN, duas instituições federais, o IFRN e a Universidade Federal do Semi-Árido (UFERSA), e duas instituições privadas; em Cajazeiras e Sousa também ofertam cursos superiores duas instituições federais - UFCG e Instituto Federal de Educação, Ciência e Tecnologia da Paraíba (IFPB), além das instituições públicas, quatro instituições privadas de ensino superior atuam em Cajazeiras e duas em Sousa.

Camacho e Soares (2009) destacam o papel do ensino superior na consolidação de Uberlândia/MG como cidade média uma vez que ao promover os fluxos intrarregionais, ampliam a importância da cidade e sua área de abrangência. Eles tomam essa importância do ensino superior para proporem que Uberlândia e sua hinterlândia constituem-se em um aglomerado urbano descontínuo.Apesar de acreditarem que o aglomerado proposto não se enquadra nos critérios oficiais que definem os aglomerados urbanos, os autores defendem que "o conceito de aglomerado deva incorporar as características da formação econômicoregional". (CAMACHO e SOARES, 2009, p. 13).

Spositoet al (2007) também reforça que atualmente o espaço de relações pode existir sem que haja a necessidade de continuidades territoriais.

\begin{abstract}
As relações espaciais que assim se conformam não estruturam áreas ou regiões, mas sobrepõem a áreas e regiões, organizadas por lógicas territoriais, outros fluxos que podem ultrapassar essas áreas ou regiões de comando de uma cidade média e o fazem, gerando estruturas espaciais em rede, cuja morfologia não contém continuidade territorial. (SPOSITO ET AL, 2007, p. 38)
\end{abstract}

A existência de aglomerados urbanosdescontínuos parece ser uma tendência na rede urbana nordestina interiorizada. Ao estudar a rede urbana, o IPEA (2002) lista oito aglomerados urbanos no Nordeste, a maioria descontínuos: Teresina(PI)/Timon(MA), Ilhéus/Itabuna(BA), Petrolina(PE)/Juazeiro(BA), Juazeiro do Norte/Crato(CE), Teixeira de Freitas/Eunápolis/Porto Seguro(BA), Sousa/Cajazeiras(PB) e Mossoró/Açu(RN).

Tomando por base a importância regional na prestação dos serviços de educação superior e a densidade dos fluxos que diariamente se direcionam para Pau dos Ferros, Cajazeiras e Sousa, e que essas três cidades detêm uma área de influencia relativamente 
extensa, mais de 100 municípios, sendo uma boa parte conjunta, apresentamos a proposição de que está se constituindo na raia divisória RN-PB-CE um aglomerado urbano-regional descontínuo formado por Pau dos Ferros, Cajazeiras e Sousa e suas respectivashinterlândias. É evidente que essa é apenas uma primeira tentativa no sentido da construção de uma nova territorialidade no interior da rede urbana nordestina, em especial, na Raia divisória RNPB-CE, novos estudos serão necessários para aprofundar a discussão e apreender essa 'nova' configuração.

\footnotetext{
${ }^{1}$ Termo utilizado por Messias Modesto Passos para designar a região fronteiriça entre os estados São PauloParaná-Mato Grosso do Sul.

${ }^{2}$ No topo da hierarquia estão as metrópoles, que se constituem nos 12 principais centros urbanos do país; em seguida as capitais regionais, 70 centros que se relacionam com o extrato superior da rede urbana, no Rio Grande do Norte, encontram-se nesta categoria Natal (nível A) e Mossoró (nível C), na Paraíba, João Pessoa (nível A) e Campina Grande (nível B); em terceiro lugar na hierarquia estão os centros sub-regionais, 169 centros com atividades de gestão menos complexa, estão nesta categoria no Rio Grande do Norte, Caicó e Pau dos Ferros (nível A) e Açu e Currais Novos (nível B), na Paraíba, Cajazeiras, Guarabira, Patos e Sousa (nível A) e Itaporanga (nível B) (IBGE, 2008).

${ }^{3} \mathrm{O}$ número de relacionamentos é calculado como o número de vezes em que, no questionário da pesquisa, o centro foi mencionado como destino. (IBGE, 2008, p. 11)

${ }^{4}$ Em 1966, no primeiro estudo sobre rede urbana realizado pelo IBGE, Cajazeiras foi considerada Centro Subregional A e Sousa e Pau dos Ferros foram consideradas Centros Sub-Regionais B, no estudo de 1978 Cajazeiras e Sousa mantiveram suas posições, o mesmo ocorrendo no estudo de 1993; já Pau dos Ferros, perdeu posição nos dois estudos subsequentes (no estudo de 1978 foi considerado Centro de Zona e no de 1993 foi considerado de centralidade d e nível 'Médio'); retomando agora no último Regic a posição de Centro Sub-regional e ascendendo para o nível A. (IBGE, 2008).

${ }^{5}$ A autora utilizou a base de dados do REGIC 1993, publicado pelo IBGE em 2000.

${ }^{6}$ Cano (1989); Andrade (1987).

${ }^{7}$ Cano (1989); IBGE (2008).

${ }^{8}$ Pau dos Ferros (RN) está localizado no entroncamento viário das BRs 405 e 226 (em pavimentação); Cajazeiras e Souza (PB) estão localizadas às margens da BR 230, com pequenos trechos de rodovias estaduais ligando-as à BR 405.

9 Termo utilizado inicialmente por Furtado, depois por diversos estudiosos da região Nordeste como Cano (1989), Andrade (1987) e Clementino (1995) para designar o sistema agricultura-pecuária (açucareiro-criatório e algodoeiro-criatório), vigentes na economia colonial e que com poucas modificações predominou no Nordeste até o final do século XIX.

${ }^{10}$ Clementino (1995).

${ }^{11}$ Para a definição dos níveis de gestão, o IBGE utilizou dados secundários referentes à presença de órgãos da administração federal nos municípios e dados do Cadastro Geral de Empresas com os endereços das sedes das empresas.

${ }^{12}$ Para a realização dessa parte da pesquisa, foram aplicados questionários nos 4625 municípios que não foram considerados centros de gestão. O questionário foi preenchido pelos técnicos das agencias do IBGE. (IBGE, 2008, p. 139).

${ }^{13}$ A ampliação dos cursos da UERN se deu no final de 2004 e os Campi do IFRN e da UFERSA, foram implantados em 2008 e 2012, respectivamente Como a base de dados utilizada no REGIC para quantificar as áreas de influências é de 2004, nem todas as mudanças foram captadas pelo documento publicado em 2008.
}

\section{Referências}

Geo UERJ - Ano 15, no. 24, v. 1, $1^{\circ}$ semestre de 2013 p. 228-255

ISSN: 1415-7543E-ISSN: 1981-9021

http://www.e-publicacoes.uerj.br/index.php/geouerj 
AMORIM FILHO, Oswaldo; SERRA, Rodrigo V. Evolução e perspectivas do papel das cidades médias no planejamento urbano e regional. In: ANDRADE, Thompson A.; SERRA, Rodrigo V. Cidades médias brasileiras. Rio de Janeiro: IPEA, 2001. 393p. p. 1-34.

ANDRADE, Manoel C. Geografia econômica do Nordeste: o espaço e a economia nordestina. 4. Ed. São Paulo: Atlas, 1987. 174 p.

ARAÚJO, Tania B. Ensaios sobre o desenvolvimento brasileiro: heranças e urgências. Rio de Janeiro: REVAN, 2000. 392p.

AVELINO, José L. O papel das cidades intermédias na promoção do desenvolvimento regional: o caso do sistema urbano local de Santarém/Almerim/Cartaxo. In: CONGRESSO DE GEOGRAFIA PORTUGUESA. 3., set. 1997. Porto, Portugal. Anais....Porto-PT, 1997. p. 465-473.

BRANDÃO, Carlos. Território e Desenvolvimento: as múltiplas escalas entre o local e o global. Campinas/SP: Ed. da UNICAMP, 2007. 238 p.

CANO, Wilson. Urbanização: sua crise e revisão de seu planejamento. In: Revista de Economia Política.Vol. 9, n 1. São Paulo: jan/mar. 1989. p. 62-82.

CAMACHO, José F; SOARES, Beatriz R. A expansão do ensino superior na definição de um aglomerado urbano descontínuo em torno da cidade de Uberlândia-MG. In:ENCONTRO DE GEÓGRAFOS DA AMÉRICA LATINA. 12., Abr. 2009. Montevideu/Uruguay. Anais.. 14 p. Disponível em: http://egal2009.easyplanners.info/area05/5098_CAMACHO_JOSE_FERNANDES.docAcess o em 20 de abril de 2012.

CAMEAM/UERN. Matrículas dos alunos nos cursos de Graduação (2010.1) e no PARFOR (2011-2012). Pau dos Ferros-RN: CAMEAM/UERN, 2012.

CASTELLO BRANCO, Ma. Luiza. Cidades médias no Brasil. In: SPOSITO, E. S.; SPOSITO, Maria E. B.; SOBARZO, O. (Orgs.) Cidades médias:produção do espaço urbano e regional. São Paulo: Expressão popular, 2006.376p. p.245-277.

CLEMENTINO, Maria do Livramento M. Economia e urbanização: o Rio Grande do Norte nos anos 70. Natal/RN: Ed UFRN, 1995. 371p.

Receitas municipais e grau de dependência dos pequenos municípios do Nordeste. Natal/RN, 1997. (texto mimeo).

CORREIA, Roberto L. Construindo o conceito de cidade média. In: SPOSITO, Maria Encarnação B. Cidades médias:espaços em transição. São Paulo: Expressão Popular,2007. 632 p. p. 23-33.

ESTEBAN Alfonso de; LÓPEZ, Alejandro El papel de lasciudades medias em España: presente y futuro. In: Revista Arquitectura COAM. Madri-ES, nº 6, p 6-16. 1989. 
FARIA, Vilmar. O processo de urbanização no Brasil: algumas notas para seu estudo e interpretação. In: ENCONTRO DA ABEP. 1., 1978, São Paulo. Anais...São Paulo, 1978. p. 89-110.

FERRÃO, João.; HENRIQUES, Eduardo B.; NEVES, Antonio O. Repensar as cidades de média dimensão. In Análise Social. Lisboa-PT,v. XXIX, p. 1123-1147. 1994.

GARCIA, Alexandrino R.; NOGUEIRA, Marly. A inserção das cidades médias mineiras na rede urban a de Minas Gerais. In: SEMINÁRIO SOBRE A ECONOMIA MINEIRA, 13, ago. 2008. Diamantina-MG. Anais ...Diamantina-MG, 16p.Disponível em: http://www.redbcm.com.br/arquivos/bibliografia/ricardo\%20e\%20marly.pdfAcesso em 20 de abril de 2012.

HESPANHOL, Antonio N. Perfil da agropecuária na porção paulista da Raia Divisória São Paulo-Paraná-mato Grosso do Sul e desempenho do programa estadual de microbacias hidrográficas na região. In: PASSOS, Messias M. (org) A Raia Divisória São Paulo-ParanáMato Grosso do Sul:cenas e cenários. São Paulo: outras expressões, 2011. 360p. p. 201-230.

IBGE - Instituto Brasileiro de Geografia e Estatística Região de Influência das Cidades 2007. Rio de Janeiro: IBGE, 2008. 201p.

- Resultados do Censo 2010.IBGE, 2010. Disponível em: http://www.ibge.gov.br/home/estatistica/populacao/censo2010/populacao_por_municipio_zip. shtm. Acesso em: 14 de dezembro de 2010.

IPEA - Instituto de Economia Aplicada. Caracterização e Tendências da Rede Urbana do Brasil: redes urbanas regionais - Norte Nordeste e Centro-Oeste. Brasília: IPEA, 2002. 90p.

MORAIS, Ione R. Diniz. Desvendando a cidade: Caicó em sua dinâmica espacial. Brasília: Ed. do SENADO, 1999. 334p.

PASSOS, Messias M. A raia divisória: geossistema, paisagem e eco-história. Maringá-PR: UEM, 2006.p. 132.

A construção da paisagem na raia divisória São Paulo-Paraná-Mato Grosso do Sul. In ENCUENTRO DE GEÓGRAFOS DE AMÉRICA LATINA, 12, Abr. 2009 - Montevideo, Uruguay. Anais...Montevideo, Uruguay 20p. Disponível em: http://egal2009.easyplanners.info/area06/6167_MESSIAS_MODESTO_PASSOS.pdf Acesso em 20 de abril de 2012.

PONTES, Beatriz M. S. As mudanças no processo produtivo capitalista e suas repercussões nas cidades médias nordestinas. In: SPOSITO, E. S.; SPOSITO, Maria E. B.; SOBARZO, O. (Orgs.) Cidades médias:produção do espaço urbano e regional. São Paulo: Expressão popular,2006. 376 p. P.327-346.

PEREIRA, Anete M. Cidade média e região:o significado de Montes Claros no norte de Minas Gerais.351f. Tese (Doutorado em Geografia). Instituto de Geografia. Universidade Federal de Uberlândia,2007. 
SOUZA, Reginaldo J. Fronteiras ou raias (?). In: PASSOS, Messias M. (org) A Raia Divisória São Paulo-Paraná-Mato Grosso do Sul: cenas e cenários. São Paulo: outras expressões, 2011. 360p. P. 17-42.

SPOSITO, Ma. Encarnação B.; ELIAS, Denise; SOARES, MAIA, Doralice S.;GOMES, Edvânia T. A. O estudo das cidades médias brasileiras: uma proposta metodológica. In: SPOSITO, Ma. Encarnação B. Cidades médias: espaços em transição. São Paulo: Expressão Popular, 2007. 632p. P. 35-67.

STEINBERGER, Marília; BRUNA, Gilda C. Cidades médias: elos do urbano-regional e do público-privado. In: ANDRADE, Thompson A.; SERRA, Rodrigo V. Cidades médias brasileiras.Rio de Janeiro: IPEA, 2001. 393 p. p. 35-77.

Artigo recebido para publicação em maio de 2013.

Artigo aceito para publicação em maio de 2013. 